\title{
Laboreal
}

Volume $17 \mathrm{~N}^{\circ} 2$ | 2021

Trabalho e Território

\section{A poda de vegetação no trabalho do eletricista de linha viva sob a ótica da ergonomia e da psicodinâmica do trabalho}

La poda de la vegetación en el trabajo del electricista de línea viva desde la perspectiva de la ergonomía y de la psicodinámica del trabajo

L'élagage de la végétation dans le travail de l'électricien sous tension du point de vue de l'ergonomie et de la psychodynamique du travail

The pruning of vegetation in the work of the lineman from the perspective of ergonomics and psychodynamics of work

Marcella Silva Ribeiro Gonçalves, Sandra Francisca Bezerra Gemma, Flavia Traldi de Lima, Renan Primo, Milton Shoiti Misuta, José Luiz Pereira Brittes, Amanda Lopes Fernandes e Eliezer Silva Franco

\section{(2) OpenEdition}

Edição electrónica

URL: https://journals.openedition.org/laboreal/18295

DOI: $10.4000 /$ laboreal. 18295

ISSN: 1646-5237

Editora

Universidade do Porto

Refêrencia eletrónica

Marcella Silva Ribeiro Gonçalves, Sandra Francisca Bezerra Gemma, Flavia Traldi de Lima, Renan Primo, Milton Shoiti Misuta, José Luiz Pereira Brittes, Amanda Lopes Fernandes e Eliezer Silva Franco, «A poda de vegetação no trabalho do eletricista de linha viva sob a ótica da ergonomia e da psicodinâmica do trabalho», Laboreal [Online], Volume 17 N² | 2021, posto online no dia 01 dezembro 2021, consultado o 05 dezembro 2021. URL: http://journals.openedition.org/laboreal/18295 ; DOI: https://doi.org/10.4000/laboreal.18295

Este documento foi criado de forma automática no dia 5 dezembro 2021.

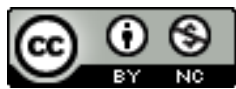

Laboreal está licenciado com uma Licença Creative Commons - Atribuição-NãoComercial 4.0 Internacional. 


\section{A poda de vegetação no trabalho do eletricista de linha viva sob a ótica da ergonomia e da psicodinâmica do trabalho}

La poda de la vegetación en el trabajo del electricista de línea viva desde la perspectiva de la ergonomía y de la psicodinámica del trabajo

L'élagage de la végétation dans le travail de l'électricien sous tension du point de vue de l'ergonomie et de la psychodynamique du travail

The pruning of vegetation in the work of the lineman from the perspective of ergonomics and psychodynamics of work

Marcella Silva Ribeiro Gonçalves, Sandra Francisca Bezerra Gemma, Flavia Traldi de Lima, Renan Primo, Milton Shoiti Misuta, José Luiz Pereira Brittes, Amanda Lopes Fernandes e Eliezer Silva Franco

\section{NOTA DO EDITOR}

Autora correspondente : Flavia Traldi de Lima

Manuscrito recebido em : 16/10/2020

Aceite após peritagem em : 30/10/2021

\section{Agradecimentos}

Os autores agradecem o apoio técnico e financeiro da CPFL Energia através do Programa de Pesquisa e Desenvolvimento Tecnológico do Setor de Energia Elétrica da ANEEL (Projeto de P\&D PD-00063-3036/2018). 


\section{Introdução}

1 O mundo do trabalho está sempre em transformação, seja na organização, regulamentação e leis que o regem, seja nos modos de produção e tecnologias empregadas. Apesar disso, existe uma constância neste cenário, que diz respeito a sua influência sobre a saúde dos indivíduos que trabalham. Em outros termos, o trabalho nunca é neutro. Pode ser fonte de desenvolvimento e saúde e auxiliar na estruturação da identidade dos sujeitos ou, por outro lado, ser gerador de doenças e lesões, tanto em termos físicos quanto psíquicos (Dejours, 2013).

2 O trabalho no setor elétrico tem sido bastante discutido pelos riscos elétricos, mecânicos, químicos, biológicos que apresenta (Guardia \& Lima, 2019; Martinez \& Latorre, 2009). Embora tenha passado por mudanças consubstanciais nas formas de gestão e estruturação, percebe-se que o setor apresenta dados significativos em termos de acidentes, doenças e mortes no trabalho ou relacionados a ele. Segundo dados da Fundação Comitê de Gestão Empresarial (FUNCOGE), de 1999 a 2013 a taxa de mortalidade no setor elétrico foi em média 4,8 vezes maior do que a dos demais setores formais da economia brasileira (FUNCOGE, 2014) [1].

Dados mais recentes do SmartLab - Observatório de Segurança e Saúde no Trabalho vinculado ao Ministério Público do Trabalho (MPT) - informam que, em 2018, a distribuição elétrica registrou 10.605 casos de acidentes de trabalho, a transmissão elétrica notificou 1.986 casos e a geração elétrica 5.542 casos (SmartLab, 2018). O processo de distribuição de energia, foco desta pesquisa, é o que também apresenta número superior de acidentes e mortes no trabalho (DIEESE, 2017).

Dentre as diferentes funcões que pode ocupar um eletricista, o Eletricista de Linha Viva de rede de distribuição de energia atua na intervenção e manutenção de redes elétricas aéreas, sem que haja a interrupção do seu fornecimento. As operações de manutenção (preventivas e corretivas) são realizadas no circuito energizado com tensões de até 500 $\mathrm{KV}$, o que requer equipamentos, ferramentas e procedimentos específicos de segurança.

5 A presente pesquisa foi realizada em uma concessionária de energia elétrica localizada no interior do estado de São Paulo com o quadro próprio de eletricistas que atuam em linha viva (serviço onde existe interação dos trabalhadores com condutor em linha energizada), com o fito de depurar mais sobre essa atividade. A pesquisa com duração de três anos, teve início em maio de 2018 por meio da parceria entre a Faculdade de Ciências Aplicadas da UNICAMP, a Concessionária de Energia Elétrica Companhia Paulista de Força e Luz (CPFL) e uma empresa de engenharia fabricante de ferramentas, a Restart Brasil.

6 Para isso realizou-se a aplicação da Análise Ergonômica do Trabalho (AET) de forma adaptada. Posteriormente foram realizadas entrevistas semiestruturadas com a equipe de LV, sendo que as falas foram tratadas conforme a Análise de Conteúdo e discutidas na perspectiva da Ergonomia da Atividade e da Psicodinâmica do trabalho.

\section{Aporte teórico}

7 Até a década de 80, havia forte predomínio dos fatores físicos, químicos e biológicos na etiologia dos danos à saúde nos ambientes de trabalho. No decorrer dos anos, cientistas 
se convenceram de que além disso, a organização do trabalho também é capaz de gerar sofrimento e adoecimento (Dejours, 1987 ; Le Guillant, 1984).

8 Atualmente há um maior conhecimento e formulação de propostas para fazer frente aos problemas psicossociais no contexto laboral, normalmente engendrados por questões ligadas à organização do trabalho.

9 Por essa razão o artigo se ancora nos pilares da Ergonomia da Atividade e da Psicodinâmica do Trabalho (PDT) a fim de alcançar resultados que estão além do que é dado, ou seja, daquilo que se encontra muitas vezes no campo do invisível da atividade de trabalho e na dimensão subjetiva daqueles que trabalham.

10 Tais referências compõem um campo de compreensão que visualiza o trabalhador não apenas como mero executante do trabalho prescrito, mas como um sujeito de ação, dotado de inteligência, valores, sentidos e emoções.

11 Privilegia-se, assim, uma abordagem atenta ao que se passa nas situações reais, ciente de que há muito mais em jogo no trabalho do que a execução de normas e procedimentos determinados externamente (Pinheiro et al., 2018).

\subsection{Ergonomia da atividade e psicodinâmica do trabalho}

12 A Análise Ergonômica do Trabalho (AET), de vertente francesa, responde às questões que surgem sobre o trabalho real. A sua principal característica é ser um método indutivo de análise do trabalho feita em campo, ou seja, baseada no trabalho efetivamente realizado pelos trabalhadores nas situações de trabalho.

Esta abordagem de análise e intervenção busca resolver os problemas da inadequação do trabalho às características humanas gerados, entre outros, por projetos de sistemas de produção, de processos, da organização do trabalho e das tarefas que foram feitas, muitas vezes a partir de estereótipos simplificados do que seria a população de trabalhadores, que geralmente são "encaixados" na produção (Pizo \& Menegon, 2010).

14 Para explicar alguns fenômenos observados, é necessário dialogar com os trabalhadores e, portanto, nenhuma análise é feita apenas de observações, por mais que estas constituam sua base, nenhum instrumento de observação pode substituir o conhecimento dos trabalhadores sobre as tarefas que realizam. Em termos conceituais, Wisner (1987) aponta que o saber do trabalhador está no mesmo nível do saber técnico científico e é condição indispensável para o sucesso da ação ergonômica.

Para além da distinção entre tarefa e atividade, ou seja, trabalho prescrito e trabalho real, que possibilita o interesse pela inteligência no trabalho, a Ergonomia da Atividade analisa aspectos relacionados às cargas de trabalho físicas, psíquicas e cognitivas. Tais cargas se interrelacionam e são descritas conforme Silva (2011) :

\footnotetext{
“A carga física está associada ao esforço físico e ao desgaste das estruturas corporais para a realização de determinado trabalho, está relacionada aos gestos, às posturas e aos deslocamentos para executar a tarefa.

A carga cognitiva refere-se às exigências mentais na realização do trabalho e pode manifestar-se nas situações onde há necessidade intensa de memorização, atenção, concentração, acuidades visual e auditiva, além de tomada de decisões.

As diferentes situações de trabalho associadas às características pessoais dos trabalhadores e à rigidez da organização do trabalho podem revelar-se como carga psíquica. A carga psíquica pode ser representada como a resultante da
} 
confrontação entre os desejos do trabalhador e da empresa" (Silva, 2011, p. 3395).

16 Vale lembrar que estão envolvidas também as variabilidades encontradas nas diferentes atividades de trabalho, tanto aquelas ligadas ao contexto organizacional (normal e incidental) quanto aos operadores (aspectos biológicos, psicológicos, estado de fadiga, etc).

17 A resposta dos trabalhadores a esta variabilidade era entendida como o afastamento do trabalho prescrito e, portanto, como um risco à qualidade da produção e aos equipamentos. Contudo, este afastamento é hoje entendido como uma forma de gestão desta variabilidade (Abrahão et al., 2009).

No trabalho dos eletricistas esta variabilidade está presente nos materiais e ferramentas, no ambiente externo de intervenção das redes, na experiência e expertise de cada trabalhador, nas relações com consumidores e com os diferentes atores da organização.

19 As más condições de trabalho, como por exemplo repetitividade, monotonia, alta demanda, colocam o trabalhador em vários perigos, mas além de trazer prejuízos para o corpo, traz também para outras dimensões da natureza humana. A ansiedade e a angústia, por exemplo, são sintomas psíquicos do risco que a nocividade das condições de trabalho impõe (Dejours, 1987).

20 A carga psíquica revela-se nas diferentes situações de trabalho associadas às características pessoais dos trabalhadores e à rigidez da organização do trabalho (Dejours, 1994 ; Silva, 2011). E em profissões de risco, como é o caso dos eletricistas, o desgaste físico e mental é particularmente intenso em relação a dos outros grupos (Primo, 2020).

21 O trabalho no setor elétrico, pelo alto grau de risco e variabilidade de tarefas repercute sobre carga de trabalho, demandando dos trabalhadores constantes regulações para poder estabelecer, por meio da atividade, a adaptação às condições impostas.

$O$ ajuste e a regulação das atividades acabam sendo expressos por meio ainda da adoção de estratégias a partir da vivência coletiva do trabalho, como forma de prevenir ou amenizar constrangimentos (Silva, 2011). Dessa maneira, os trabalhadores criam estratégias que podem ser individuais ou coletivas para lidar com o real do trabalho.

As estratégias defensivas coletivas caracterizam-se pela presença de condições externas reais que geram sofrimento e são construídas no coletivo a partir do estabelecimento de regras e consenso entre membros de uma determinada categoria profissional (Dejours, 1987 ; Mendes, 1995).

24 Tais estratégias podem permitir ao sujeito uma estabilidade na luta contra o sofrimento, que, em outras situações, seria incapaz de garanti-la apenas com suas defesas individuais.

Assim sendo, a Psicodinâmica do Trabalho (PDT) estuda os aspectos menos visíveis que são vivenciados pelos trabalhadores ao longo do processo produtivo e que são trabalhados nesse artigo, tais como sofrimento e prazer no trabalho, mecanismos de reconhecimento e cooperação e estratégias coletivas de defesa. 


\subsection{A relação saúde e trabalho mediante os riscos do setor elétrico}

exigido na área eletromagnética e à atenção constante para não haver erro. Existem também uma alta carga psíquica devido à periculosidade característica do serviço. Há na literatura relato sobre a associação destes fatores à ameaça da perda do emprego e às responsabilidades inerentes ao trabalho (Castro, 2016). principalmente na coluna vertebral, ombros, punhos e mãos, tais problemas foram associados ao trabalho estático de membros superiores, combinado aos esforços físicos, resultantes de gestos de manipulação e pressão de ferramentas ou estruturas e das dificuldades que a busca pelo melhor campo de visão impõe (Vasconcelos et al., 2011). demandas e exigências por qualidade, as responsabilidades, as possibilidades de progressão na carreira, a segurança no emprego, o apoio social, o reconhecimento no trabalho, o convívio com o perigo e o risco, que podem levar ao uso abusivo de álcool, à depressão, ao sobrepeso, à obesidade e aos transtornos mentais comuns nesta população (Gemma et al., 2019 ; Souza et al., 2010, 2012).

Cumpre dizer que, com o avanço de distintas formas de produção e contratação que geralmente estão associadas à precarização do trabalho, em particular do trabalho terceirizado, vê-se a possibilidade de degradação deste tipo de trabalho, na medida em 
que a quantidade de terceirizados tem aumentado consideravelmente no setor (Alves et al., 2020 ; Castro, 2016 ; Lima \& Oliveira, 2021).

\section{Método}

A pesquisa ocorreu entre 2018 e 2020 em uma das estações de abastecimento de energia de uma concessionária localizada no interior de São Paulo.

m termos metodológicos a pesquisa contou com a aplicação das primeiras etapas da Análise Ergonômica do Trabalho (AET) (Guérin et al., 2001), que incluíram a análise da demanda, levantamento de informações gerais, análise da tarefa e observações globais da atividade.

Realizou-se entrevista coletiva com os eletricistas para que selecionassem, dentre as 123 atividades destinadas aos Eletricistas da Companhia, aquelas consideradas mais críticas. 0 grupo, que à época somavam 8 eletricistas, bem como demais atores da produção consultados (gestores e técnicos) indicaram a tarefa de Poda de Vegetação como uma das atividades mais críticas segundo os critérios de Dificuldade, Duração e Frequência.

A análise da tarefa de Poda de Vegetação ocorreu por meio de observações de campo a partir de visitas aos locais de trabalho dos eletricistas e endereços de atuação, considerou-se também as verbalizações consecutivas e confrontações, após a finalização de cada atividade, já que por condições de segurança não se pode interagir simultaneamente com os operadores no exercício da atividade, sobretudo no cesto aéreo.

39 Este estudo tem aval do Comitê de Ética em Pesquisa (CAAE : 16531119.0.0000.5404) sendo devidamente registrado por meio de diários de campo, imagens (fotos e vídeos) e gravações de áudios. Posteriormente, foram realizadas entrevistas semiestruturadas com os 8 eletricistas de linha viva (equipe completa da estação de abastecimento de energia), previamente organizadas em roteiro contendo indagações acerca do conteúdo da atividade de poda de vegetação, bem como as dificuldades e potencialidades vivenciadas pelos trabalhadores.

Os ELV possuem tempo de experiência na funçãoe somente exercem este trabalho depois de ter atuado em linha morta (desenergizada) e serem habilitados em treinamentos específicos para redes energizadas. Na Tabela 1 temos a distribuição dos ELV por tempo de empresa e na função específica da linha viva. 
Tabela 1 : Tempo de experiência dos ELV na empresa e na função de Linha Viva

\begin{tabular}{|c|c|c|}
\hline Anos & Empresa & Linha Viva \\
\hline 0 a 5 & ELV3, ELV5, ELV8 & ELV2, ELV3, ELV5, ELV8 \\
\hline 6 a 10 & - & ELV1, ELV4 \\
\hline 11 a 15 & ELV4 & ELV6, ELV7 \\
\hline 16 a 20 & ELV1 & - \\
\hline 21 a 25 & ELV6 & - \\
\hline 26 a 30 &
\end{tabular}

Tabela 1 : Tempo de experiência dos ELV na empresa e na função de Linha Viva

41 As entrevistas foram realizadas no prédio administrativo da estação de abastecimento, em uma sala reservada, em duplas, de acordo com a atuação diária de trabalho. Todas as entrevistas foram gravadas após o consentimento prévio dos participantes. No total obteve-se aproximadamente 4 horas de áudio. As gravações foram transcritas a fim de serem analisadas por meio da Análise de Conteúdo do tipo Categorial (Bardin, 2011).

A Análise de Conteúdo prevê o desenvolvimento de três fases fundamentais, a considerar, a 1) Pré-análise, mediante organização do material transcrito, preparação e leitura flutuante do texto, 2) Exploração do Material, pela escolha das categorias de análise de acordo com a repetição de temas e 3) Tratamento dos resultados, no qual o texto passou por inferência e interpretação.

As categorias extraídas da Análise de Conteúdo contemplaram : esforços e demandas da tarefa de poda de vegetação ; relação com clientes ; relação com terceirizados ; relação com a organização do trabalho; prazer e trabalho.

Para análise dos dados utilizou-se as contribuições teóricas da Ergonomia da Atividade e da Psicodinâmica do trabalho. Nesse sentido, conceitos como sofrimento e prazer no trabalho, mecanismos de reconhecimento e cooperação e estratégias coletivas de defesa, foram fundamentais para permitir dar sentido e explicação ao material produzido neste artigo.

\section{Resultados e Discussão}

\subsection{Esforço físico, cognitivo e carga psíquica}

$\mathrm{Na}$ concessionária estudada a poda de vegetação é um serviço realizado constantemente pelas equipes, sejam elas de linha morta ou linha viva. A finalidade dessa atividade é manter a rede elétrica em condições de acesso e diminuir o risco de 
danos nos cabos. Isso faz com que o trabalho de poda seja essencial na prevenção de ocorrências e, por conseguinte, para a companhia.

A atividade realizada por ELV ocorre em duplas, que se alternam durante o itinerário nas posições de executor e eletricista supervisor da tarefa, denominado "guardião da vida". O executor trabalha alocado em cesto aéreo com acesso aos galhos das árvores, operando a serra hidráulica de corte, enquanto o guardião da vida, permanece no solo, realizando apoio, observação, zelo e supervisão sob a atividade realizada peloeletricista executor.

Figura 1 : ELV em cesto aéreo fazendo a poda de árvore com uso da serra hidráulica

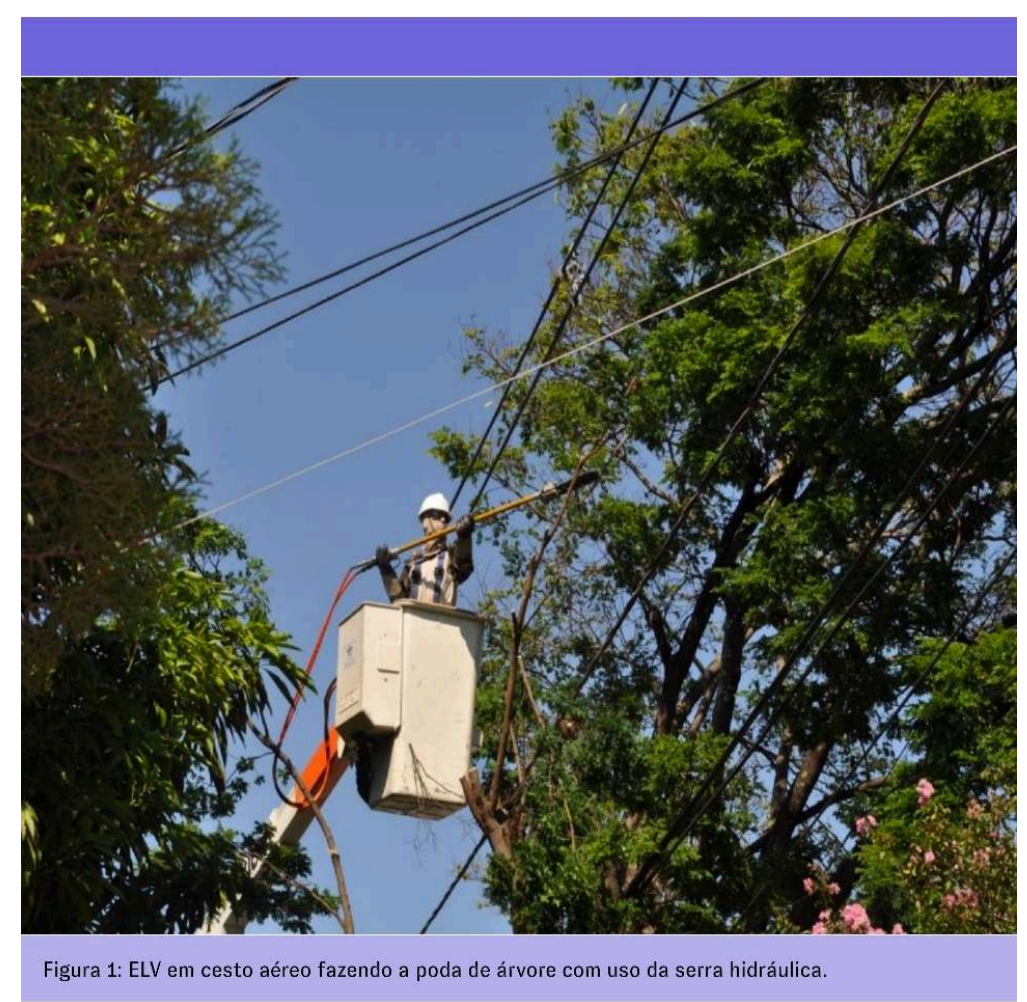

Figura 1 : ELV em cesto aéreo fazendo a poda de árvore com uso da serra hidráulica

Os eletricistas entrevistados alegaram que, quanto à natureza, a tarefa de poda de vegetação exige bastante esforço, de modo a envolver dificuldade postural e alto risco.

Em relação a serra hidráulica, equipamento exclusivamente utilizado nesta tarefa, relatou-se que apresenta peso significativo $(8 \mathrm{~kg})$. Quanto à duração, ela pode durar de 1 a 3 horas ou até dias, a depender da árvore. Quanto a frequência é considerada alta pelos eletricistas em comparação a outras tarefas, como exemplo troca de postes e manutenção de cruzetas, pois é realizada, no mínimo, uma vez por dia. Três dias da semana são alocados somente para a execução de poda de vegetação, no entanto, no decorrer da pesquisa observou-se que esse número sofreu variações, aumentando por vezes a frequência de sua realização. Dentre os esforços que permeiam essa atividade elencou-se 2 tipos :

Esforço físico : Em relação ao eletricista executor, que opera no cesto aéreo, identificou-se as seguintes problemáticas: Os movimentos das mãos são dificultados por conta da espessura da luva (que varia entre 1,02 a 2,29 cm); Movimentos dos braços 
dificultados por conta do mangote de proteção (manga de proteção para os braços e antebraços, que ficam envolvidos e resguardados do contato com produtos ou objetos prejudiciais à pele); Movimentos com um braço esticado e outro flexionado, ou ambos esticados ou ambos flexionados, acima do nível dos ombros, para ter melhor visão e alcance na execução ; Flexão de tronco ; Repetição de uma subtarefa (manuseio do cesto aéreo) e vibração de serra, que associada às posturas desconfortáveis, pode potencializar os danos nos ombros, braços, antebraços, pulsos, mãos e dedos.

Em relação ao eletricista supervisor ou guardião da vida, aquele que observa e zela pelo trabalho do eletricista executor posicionado ao chão, identificou-se esforços físicos do tipo : Extensão de pescoço devido a necessidade de supervisão da atividade que é realizada no cesto aéreo, implicando no olhar constante direcionado para o alto, visto que ele se encontra no solo e necessita acompanhar o desenrolar da atividade do executor; Carregamento de pedaços de troncos e galhos de árvore que caem no solo, demandando flexões de tronco e esforço físico no carregamento e acomodação da carga.

51 Absolutamente todos os eletricistas de linha viva associam lesões e dores nos braços, antebraços, punhos, cotovelos e ombros à poda de vegetação.

“... [a dor] só veio aparecer depois que eu vim pra linha viva. Eu não sei se por causa da luva, porque a luva é mais grossa, entendeu? Se é por causa da serra porque a gente fica muito mais tempo com ela na mão. Não sei te dizer, entendeu ? Se é em função dos dois juntos, entendeu ?" (ELV2)

"Se você pára de podar árvore, geralmente dor que você tem no ombro, cotovelo, punho, ela diminui ou some, aí você volta a podar árvore de novo, volta a dor de novo" (ELV7)

"Depois que eu entrei na linha viva... eu tenho 5 anos aqui e menos de 1 ano com a linha viva. Nos outros quatro anos não tinha dor não..." (ELV8)

Assim como descreve Silva (2011) sobre as cargas de trabalho físicas, nota-se que o trabalho executado pelos Eletricistas de Linha na tarefa de Poda de Vegetação apresenta esforços físicos significativos, relacionados à intensificação e repetição de movimentos e posturas. Para além disso, tais esforços são realizados em ambiente externo, no qual os trabalhadores se mantêm expostos às condições climáticas de alta temperatura e calor, umidade, vento e outros, potencializando a sobrecarga de trabalho.

Esforço cognitivo : O esforço cognitivo que essa atividade demanda é igualmente intenso e extenso, pois são diversos os cuidados e decisões que o eletricista deve tomar durante a execução completa da atividade de poda, a saber : Variedade de vegetação ; Podar sem abater a árvore (pois isso pode gerar multa para a empresa) ; Cuidado com queda de galhos na casa dos consumidores, pedestres e no próprio material de trabalho; Identificar melhor maneira de posicionar o caminhão; Maneiras de manusear a serra; Escolha da melhor postura em função do risco (contato com as linhas energizadas).

54 Tais condições demonstram as distintas cargas cognitivas (Silva, 2011) presentes no trabalho dos eletricistas de linha viva, no qual manifestam-se situações que exigem intensa acuidade visual, tomadas de decisões assertivas, atenção e concentração para evitar qualquer tipo de prejuízo à concessionária, bem como a própria saúde e segurança, dado que falhas em um trabalho de alto risco podem ser fatais. 
Diante das dificuldades e esforços físicos e cognitivos apresentados pela tarefa, os operadores criaram algumas estratégias como revezamento na realização da atividade por turnos, no qual quem realiza a função de guardião da vida em um período altera a função como executor e pequenas pausas durante o trabalho (aproximadamente 5 minutos a cada hora trabalhada).

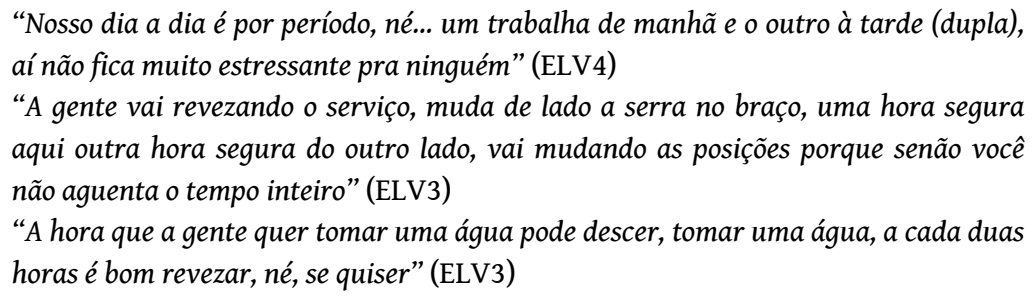

56 Carga psíquica : Além dos aspectos físicos e cognitivos apontados, houve uma verbalização significativa por parte de um dos entrevistados que demonstrou que a poda de vegetação não representa o trabalho dos eletricistas. Quando questionados sobre a importância dessa atividade, um dos ELV trabalhador respondeu "é serviço de jardineiro, né ? Não é serviço de linha viva, linha viva faz manutenção, né ?" (ELV1).

A carga psíquica, que pode ser representada como a resultante da confrontação ente os desejos do trabalhador e da empresa (Silva, 2011), é demonstrada através do descontentamento na realização de uma tarefa que não representa a natureza do ofício.

Dentro desse contexto, desempenhar, de forma habitual, uma atividade que o sujeito não considere como a sua atividade principal pode ser fonte de sofrimento. Por mais que esta atividade possa ser inerente e essencial para o trabalho, realizá-la com maior frequência, em relação às atividades próprias de manutenção, pode ser a causa de insatisfação profissional, desencadeadora de sofrimento.

\subsection{Relação com clientes}

Durante a pesquisa de campo presenciou-se diversas situações de interação dos eletricistas com transeuntes e clientes, de duração variável, entre 5 e 10 minutos, quase todos os dias. Estas estavam direcionadas à sdvidas sobre o serviço que estava sendo realizado, reclamações sobre postes com luzes queimadas (serviço de responsabilidade da prefeitura) e pedidos de retirada de árvores condenadas.

60 Sobre esse aspecto, observou-se uma interrupção do raciocínio criado para executar a atividade e/ou realizar a supervisão do trabalho, tempo acrescido para finalizá-la, além de, em determinados casos, estresse gerado a depender da demanda colocada pelo interlocutor. Em geral, os eletricistas interrompiam a atividade para explicar que a poda de árvores que não alcançam a fiação, bem como o conserto de postes de luz, são de responsabilidade da prefeitura.

61 A determinação da concessionária é que a poda de vegetação seja realizada de forma a criar um "V" na árvore. Esse tipo de poda impede que galhos e folhas encostem no fio gerando a interrupção da energia (cf. Figura 2). 
Figura 2 : Poda em “ V »

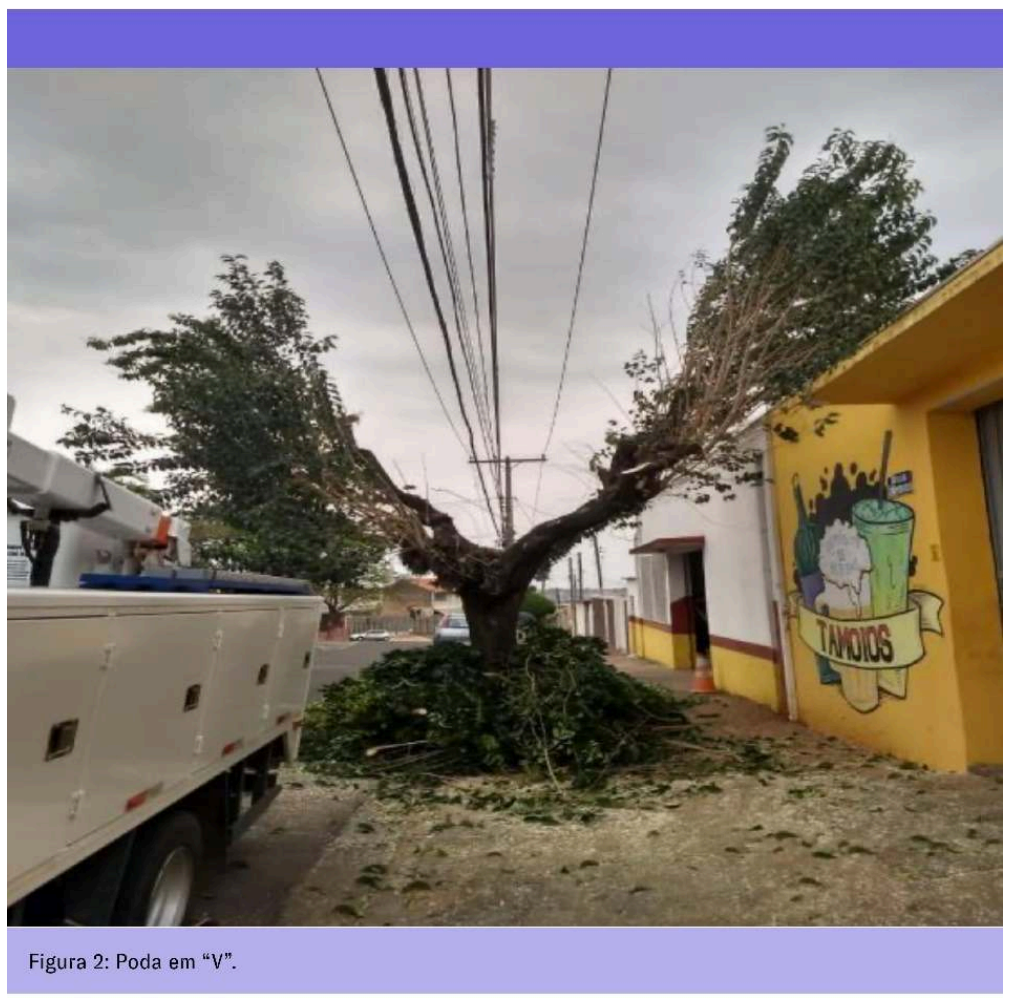

Figura 2 : Poda em “ $\vee$ »

62 A referida poda causa estranheza e, por vezes, descontentamento à população e aos clientes, pois o entendimento é de que este tipo de poda seria drástica, podendo causar a perda completa da árvore. Quando questionado sobre a relação dos trabalhadores com os clientes e transeuntes, um dos eletricistas comentou :

"normalmente, após a gente terminar a poda, antes de você terminar de guardar as ferramentas ali, já vários clientes passam e 'nossa, vocês acabaram com a árvore!' 'nossa, que poda feia, que poda horrível !' 'por que que já não cortou tudo ?'. (...) Então todo esse drama aí em relação aos clientes a gente vivencia diariamente isso aí" (ELV1)

63 Para além disso, a relação com os clientes também se dá a partir de reclamações, reivindicações, explicações e busca de razões para problemas e falhas no serviço, afinal os ELV "representam" a companhia aos olhos da população. No contexto da poda de árvore, pode haver manifestações de agressividade por parte do cliente, que considera o eletricista como sendo o porta-voz único da empresa.

Os constrangimentos, nestes casos, podem ser diversificados e de forte intensidade. Para isso, cada operador necessita encontrar estratégias de enfrentamento (individual ou coletiva) para superar estes desafios. Um exemplo de estratégia individual é a aceitação e não confrontação. Quando questionado sobre experiências com os clientes, um dos participantes explanou a seguinte situação :

"esses dias a gente tava podando, tinha uma mulher gritando, xingando “vocês têm autorização pra fazer isso?" [Pesquisadora: o que vocês responderam ?] não adianta a gente entrar em conflito com a população, né... até porque tem os caminhos da empresa pra você tá fazendo a reclamação, 
né... [Pesquisadora : como vocês lidam com isso ?] Ouve por aqui e sai por aqui, né... tem que ser profissional... é comum isso" (ELV1)

“aí os amigos da gente adiciona o nome da gente lá nos comentários e a gente fala, parabéns a equipe que fez a poda, e o povo reclama com a gente. Até o João [nome fictício], que aposentou, fez uma poda aí saiu no jornal, aí o pessoal mandou a foto, adicionaram nosso nome e eu adicionei o nome do João e tal, e disse parabéns pelo serviço, muito bonito e tal. [Pesquisadora : e o jornal criticando ?] Sim, o jornal coloca e o povo crítica, e a gente só coloca

fogo né" (ELV4)

suportar uma realidade que isoladamente com as suas defesas individuais ele não conseguiria suportar. Nesse sentido de coletividade, os indivíduos se unem para construir uma estratégia defensiva comum (Dejours, 2004).

uma das podas saiu em um jornal virtual da cidade, criticando a atuaça o dos eletricistas. O grupo reagiu brincando com a situação :

67 Para Molinier (2013), as brincadeiras, apelidos e outras formas de descontração se configuram com uma maneira de enfrentamento das dificuldades do trabalho, ou seja, como estratégias defensivas psíquicas inconscientes necessárias para que os trabalhadores suportem o sofrimento.

\subsection{Relação com terceirizados}

68 Um estudo elaborado pela DIEESE (2017) destaca o alto grau de terceirização e precatização no setor elétrico, o que, em algumas empresas, representa cerca de $80 \%$ da força de trabalho. Estudos mostram o impacto desta forma de contratação na construção identitária (Rabelo et al., 2016), no aumento dos acidentes e das doenças ocupacionais entre os profissionais contratados (Coutinho, 2015).

Embora os ELV que participaram da pesquisa sejam do quadro de funcionários prórios, os mesmos relataram como a má qualidade do trabalho terceirizado implica em prejuízos nas atividades de poda de vegetação que exercem.

Uma situação relatada diz respeito ao crescimento exacerbado de brotos e dificuldade demanutenção posterior.

\footnotetext{
“Agora, quando é feita a poda de forma incorreta, que às vezes, a empreiteira [empresa terceirizada] faz, aí passa 2 anos a gente volta pra podar lá e tá cheio de toco, né... aí a gente sofre pra danar, é muito mais desgastante pra retirar todos esses tocos, pra deixar ela em condições aí de manutenção" (ELV1)
}

71 Foi observado em campo e nas verbalizações dos eletricistas, que as dificuldades no campo vêm aumentando devido às más, porém ágeis formas de realização da poda pelas empresas terceirizadas, fenômeno que os eletricistas de linha viva julgam ser advindas do processo de precarização do trabalho das empreiteiras, que incluem falta de formação dos indivíduos e aceleração do trabalho já que os mesmos atuam por demanda. 


\subsection{Relação com a organização do trabalho}

72 A relação dos ELV com a organização do trabalho, bem como com as lideranças, apresentou características contraditórias, dado que ao mesmo tempo que se tem autonomia para a realização do trabalho, estão sendo incorporadas ferramentas de monitoramento das tarefas. 0 monitoramento é mais recente, muito dele ainda está em processo de implantação e parece atrelado ao uso dos dispositivos eletrônicos nas atividades de trabalho por meio de smartphones e tablets.

Sabe-se que as situações reais de trabalho são dinâmicas e instáveis e derivam das ferramentas, máquinas, estruturas, chefes e hierarquia, além dos clientes e dos próprios colegas e demais membros das equipes de trabalho. As pesquisas em ergonomia da atividade deixam evidente que não há nenhum tipo de trabalho que fuja destes determinantes (Dejours, 2013 ; Falzon, 2016 ; Guérin et al., 2001).

No entanto, embora existam normas de segurança e qualidade e prescrições referentes ao Passo Padrão Operacional (POP) [2] da companhia, como mencionado anteriormente, a realidade do trabalho dos ELV é marcada por variabilidades incapazes de serem totalmente antecipadas.

Isso faz com que, em um trabalho de alto risco, seja de extrema importância certa margem de manobra para operar com flexibilidade e autonomia. É certo que no contexto do setor elétrico, que envolve alto risco, existem normas que são inegociáveis, como a utilização dos equipamentos de proteção individual e coletivo e operações padrões que garantem a segurança dos eletricistas.

Ou seja, alcançar este equilíbrio é tarefa complexa e demanda muitas estratégias por parte dos operadores, fundada na experiência, para compatibilizar parâmetros que às vezes podem ser conflitantes, como a questão da segurança e do tempo para realização das tarefas. Faz-se necessário que, a organização compreenda essa distância inevitável entre o prescrito e o real, principalmente no trabalho no setor elétrico, por conta dos riscos que ele envolve.

Dejours (1987) explica esse fenômeno indicando que em todas as circunstâncias os operadores contornam os regulamentos, infringem procedimentos e ordens, não pelo prazer de transgredir ou de desobedecer, mas porque é preciso lidar com as anomalias e imprevistos que inevitavelmente surgem para atrapalhar o funcionamento da produção.

78 Em relação à organização, os ELV indicam que a companhia compreende que imprevistos acontecem e, por lidarem com alta voltagem, têm total autonomia para se recusar [3] ou realizar a tarefa prescrita de outras formas, desde que resguardadas as questões de segurança do trabalho.

79 Ademais, anda há expressão de sentimentos por parte dos ELV de certa falta de reconhecimento material pela organização - que parece ter sofrido transformações ao longo da carreira e trajetória histórica da companhia - considerando que este tipo de trabalho envolve alto risco.

Ao mesmo tempo, em outras falas, os ELV que demonstraram vivenciar situações de reconhecimento simbólico advindo das hierarquias e pares, aspecto que, de acordo com Dejours (2004) é fundamental para o favorecimento da saúde mental no trabalho. 
“Quando a liderança ou os colegas, falam, 'nossa você trabalhou bem'! Parece que ficamos incentivados a sempre fazer o melhor" (ELV4)

"Trabalho digno é quando você ta executando uma função que as pessoas reconhecem, que você olha pra trás e você vê "nossa, eu fiz aquilo ali” (ELV1)

81 O reconhecimento tem papel fundamental na possibilidade de transformação do sofrimento patogênico em sofrimento criativo, aquele capaz de se transformar em prazer e experiência estruturante. A dinâmica do reconhecimento traz a possibilidade de construção de um novo estado de saúde, identidade e sentido no trabalho (Lancman \& Sznelwar, 2011).

\subsection{Prazer e trabalho}

Neste estudo, as vivências de prazer manifestaram-se no reconhecimento social, na satisfação em trabalhar numa área que permite aprendizagens constantes, na autonomia para realizar as atividades em campo, nas relações saudáveis com os colegas e na possibilidade de transformação pessoal e da comunidade. Tais vivências são indicadoras de saúde no trabalho, proporcionam estruturação psíquica e expressão da subjetividade (Dejours, 2004), e talvez ainda representem fatores protetores em relação ao adoecimento.

Na sua relação com a comunidade, o prazer emana da realização de uma atividade essencial que se faz sem o desligamento de energia. Trocar um poste, fazer manutenção de estrutura, até mesmo podar uma árvore em LV são atividades bastante complexas e poder realizá-las sem afetar nenhum estabelecimento (residências, escolas, hospitais, fábricas e lojas, dentre outros) com o desabastecimento elétrico é componente gratificante para os eletricistas :

"é muito legal fazer parte de ser um eletricista de distribuição... de poder fazer num temporal, reestabelecer a energia... (...) a linha viva é muito legal porque você não desliga ninguém... você faz todo o serviço e, se brincar, nem percebe que você tá... (ELV7 - o pessoal nem sabe se desligou... entendeu ?) é mais gratificante.. se você fazer uma estrutura que demora metade do dia, você desce as vezes extasiado... você desce e olha e fala... a gente fez isso... a qualidade do serviço..." (ELV8)

E o trabalho, apesar de comportar uma elevada frequência da atividade de poda, é considerado diversificado, gerando aprendizagens constantes. Destaca-se que, na perspectiva da ergonomia construtiva (Falzon, 2016), quando um ofício demanda e promove condições adequadas de aprendizagem ele se aproxima dos ideais humanos de desenvolvimento.

Há, ainda, um sentimento de heroísmo e de orgulho em se pertencer à linha viva, pois é uma atividade realizada por poucos eletricistas e só os melhores são escolhidos para essa categoria, de acordo com a fala dos próprios trabalhadores. Inclusive há uma alusão de comparação do caminhão de serviço utilizado em LV com um tanque de guerra :

\footnotetext{
"o caminhão nosso parece um tanque de guerra, tem que ter de tudo, porque o profissional da linha viva ele faz tudo, então nosso caminhão tem que estar preparado pra executar qualquer tipo de tarefa. (...) Somos um profissional
} 
diferenciado porque fazemos de tudo e nosso veículo tem todo tipo de ferramenta" (ELV5)

Além dos aspectos mencionados relacionados ao próprio trabalho e à organização, há o quesito subjetivo e individual, de que muitos trabalhadores estão ali por ser a realização de um sonho, associado ao gosto pela profissão e pela própria empresa para a qual trabalha atualmente :

"eu sempre gostei da função de eletricista, de trabalhar na área, executar as funções, o fato de gostar já estimula você continuar" (ELV1)

Também são motivados pelo risco que para eles é sinônimo de trabalho desafiador. Nesse sentido poderíamos levantar os aspectos de virilidade associados às profissões de risco, exercidas majoritariamente por homens, para enfrentamento do medo (Molinier, 2013).

\footnotetext{
"é desafiador porque imagina, você tá ali naquele cesto 11 mil volts passando ali, e você em contato com ele, você pega uma ferramenta e ouve o barulho dele, então é desafiador pra gente, a hora que você desce você olha pra cima e pensa, olha o que eu acabei de executar, acho bacana, acho muito legal, gratificante" (ELV3)
}

É evidente o orgulho do grupo por realizar uma tarefa de maneira a não causar nenhum distúrbio ou transtorno para a população. Isso se demonstra como um valor, um julgamento que se faz de utilidade do próprio trabalho, que é socialmente reconhecido. Mesmo diante de tantos riscos e dificuldades associados nessa análise da poda de vegetação ainda assim evidenciou-se grande motivação nos ELV para enfrentar os desafios que este trabalho demanda e seus prováveis efeitos sobre a saúde.

\section{Conclusão}

Neste estudo, foi possível identificar as principais problemáticas enfrentadas por eletricistas de linha viva de redes de distribuição de energia elétrica no que diz respeito aos aspectos relacionados ao trabalho na tarefa de poda de vegetação.

Sabe-se que há uma série de riscos que o trabalho com a linha energizada pode engendrar, afetando diretamente as condições de execução da atividade e de saúde e segurança dos operadores.

Trabalhar com energia elétrica é o fator de risco preponderante deste trabalho em linha viva, pois é notório o conhecimento sobre as possíveis graves consequências no caso de acidentes. Entretanto, na contramão das pesquisas realizadas no campo, esse artigo demonstra que, na concessionária estudada, a atividade de poda de vegetação apresentou maiores implicações para os eletricistas

Os resultados permitiram explicitar problemáticas do trabalho relacionadas a esforços físicos, cognitivos e carga psíquica, relação com os clientes, relação com terceirizados, relação com organização do trabalho e prazer no trabalho.

3 Tais aspectos, de maneira geral, evidenciaram a frequência e intensidade de realização da tarefa de poda de vegetação, associada a posturas críticas capazes de favorecer o surgimento de queixas relacionadas a lesões e dores nos braços, antebraços, punhos, cotovelos e ombros. Também demonstraram como a variabilidade de situações e 
cenários no trabalho exigem extrema atenção e tomadas de deciões assertivas para evitar acidentes, apontando para esforços cognitivos significativos. Do mesmo modo, identificou-se determinada carga psíquica no trabalho oriunda da confrontação entre a natureza da tarefa e o ofício de eletricista, potencial promotora de sofrimento.

Sobre a relação com os clientes, identificou-se que essa interação pode corroborar com constantes interrupções do trabalho, bem como do raciocínio e planejamento empregado pelos eletricistas para execução da tarefa. A relação com os clientes também é permeada por conflitos desencadeados por reclamações sobre falhas no serviço de energia e também pelo descontentamento da população com a Poda em $\mathrm{V}$, interpretada como um tipo de poda drástica. Estratégias psíquicas individuais de aceitação, e coletivas associadas a ironias, são visualizadas como formas de enfrentamento e proteção da saúde mental.

A Poda em V também está associada a relação com os terceirizados, ou seja, com as empresas terceirizadas contratadas pela companhia para a realizaçaõ de poda de vegetação, visto que de acordo com os ELV a precarização imputada à essa modalidade de contratação reverbera na má qualidade do trabalho prestado, que gera acréscimo nas demandas de serviço.

Sobre a relação dos eletricistas com a organização do trabalho, identificou-se contradições que envolvem a implementação de controle por sistemas da informação e certa flexibilidade para autonomia nas tomadas de decisão, aspecto encarado como fundamental em atividades que envolvem variabilidades de situação de trabalho e alto risco.

Ao mesmo tempo, embora tenham sido consideradas vivências associadas a sofrimento no trabalho, o estudo evidenciou situações permeadas por reconhecimento social, de hierarquias e pares, satisfação em trabalhar numa área que permite aprendizagens constantes e autonomia para realizar as atividades em campo, fatores essencialmente importantes para a promoção de saúde mental no trabalho.

Entende-se que pesquisas como essa, contribuem para ampliar discussões sobre saúde mental e trabalho, campo ainda pouco explorado em pesquisas científicas realizadas no setor elétrico.

\section{BIBLIOGRAFIA}

Abrahão, J., Sznelwar, L., Silvino, A., Sarmet, M., \& Pinho, D. (2009). Introdução à Ergonomia : da Prática à Teoria. São Paulo : Blücher.

Abracopel (2020). Anuário estatístico de acidentes de origem elétrica - Ano base 2019. Salto : Abracopel.

Alves, A., Filho, C., Santos, N., \& Souki, G. (2021). Fatores que influenciam os acidentes de trabalho : uma análise multidimensional no setor elétrico. Gestão \& Produção, 27(2), 1-17.

Bardin, L. (2011). Análise de conteúdo. São Paulo : Ed. 70. 
Bordignon, S., Martins, M. S., Reinehr, R., Araldi, J., \& Pandolfo, A. (2008). Análise da Segurança em Instalações e Serviços em Eletricidade nas Cooperativas e Concessionárias de Distribuição de Energia Elétrica no Estado do Rio Grande do Sul. In : Anais do XXVIII Encontro Nacional de Engenharia de Produção - ENEGEP. Rio de Janeiro.

Castro, M. (2016). Quando as luzes não se apagam... A gestão coletiva dos riscos na manutenção em rede energizada (Dissertação de Mestrado). Universidade Federal de Minas Gerais, Brasil.

Coutinho, G. (2015). Terceirização : máquina de moer gente trabalhadora. São Paulo : LTr.

Dejours, C. (1987). A loucura do trabalho : estudo de psicopatologia do trabalho. São Paulo : Oboré Editorial.

Dejours C. (1994). A carga psíquica no trabalho. São Paulo : Atlas.

Dejours, C. (2004). Subjetividade, trabalho e ação. Revista Produção, 14(3), 27-34. https://doi.org/ $10.1590 /$ S0103-65132004000300004

Dejours, C. (2013). A sublimação, entre sofrimento e prazer no trabalho. Revista Portuguesa de Psicanálise, 33(2), 9-28

DIEESE - Departamento Intersindical de Estatística e Estudos Socioeconômicos. (2017) Privatização, desnacionalização e terceirização no setor elétrico brasileiro (Relatório Técnico). Brasília : Ministério do Trabalho e Emprego.

Falzon, P. (2016). Ergonomia Construtiva. São Paulo : Edgar Blucher.

FUNCOGE (2014). Relatório de Estatísticas de Acidentes do Setor Elétrico Brasileiro. Rio de Janeiro : Fundação Comitê de Gestão Empresarial.

Gemma, S., Primo, R., Brittes, J., Misuta, M., \& Lacusta Jr, E. (2019). Ergonomic and Psychosocial Aspects of Electrical Energy Maintenance Activities on Transmission Lines. In S. Bagnara et al. (Eds.), Proceedings of the 20th Congress of the International Ergonomics Association (IEA 2018) (pp. 1757-1760). Springer, Cham. https://doi.org/10.1007/978-3-319-96071-5_180

Gonçalves, M. (2020). Poda de vegetação em linha viva : complexidade e risco na atividade dos eletricistas (Dissertação de Mestrado). Universidade Estadual de Campinas, Faculdade de Ciências Aplicadas, Limeira, Brasil.

Guardia, M., \& Lima, F. (2019). Cooperação e relações de Confiança : a construção da segurança e da saúde no trabalho de alto risco. Laboreal, 15(1), 1-23. https://doi.org/10.4000/laboreal.1331

Guérin, F., Kerguelen, A., Laville, A., Daniellou F., \& Duraffourg, J. (2001). Compreender o trabalho para transformá-lo : a prática da ergonomia. São Paulo: Edgard Blucher.

Guimarães, L., Fischer, D., \& Bittencourt, L. (2004). Avaliação da carga de trabalho de eletricistas em três sistemas para subida em poste. In Anais do XIII Congresso Brasileiro de Ergonomia. Fortaleza. Disponível em http://www.producao.ufrgs.br/arquivos/publicacoes/93_22_lia_abergo2004.pdf

Lancman, S., \& Sznelwar, L. (2011). Christophe Dejours : da psicopatologia à psicodinâmica do trabalho. Rio de Janeiro : Editora Fiocruz.

Le Guillant, L. (1984). Quelle psychiatrie pour notre société ? Paris : Érès.

Lima, M., \& Oliveira, R. (2021). Precarização e acidentes de trabalho : os riscos da terceirização no setor elétrico. Revista Brasileira de Saúde Ocupacional, 46(6), 1-11. https://doi.org/ 10.1590/2317-6369000024019

Martinez, M., \& Latorre, M. (2009). Fatores associados à capacidade para o trabalho de trabalhadores do Setor Elétrico. Cadernos de Saúde Pública, 25(4), 761-772. 
Melo, L., Lima, G., Gomes, N., \& Soares, R. (2003). Segurança nos Serviços Emergenciais em Redes Elétricas : Os Fatores Ambientais. Revista Produção, 2(13), 88-101. https://doi.org/10.1590/ S0103-65132003000200009

Mendes, A. (1995). Aspectos psicodinâmicos da relação homem-trabalho : as contribuições de C. Dejours. Psicologia : Ciência e Profissão, 15, 34-38. https://doi.org/10.1590/

S1414-98931995000100009

Molinier, P. (2013). o trabalho e a psique - Uma introdução à psicodinâmica do trabalho. Brasília : Paralelo 15.

Pinheiro, S., Santos, M., \& Cunha, L. (2018). Digitalização do trabalho no INSS : tensões e estratégias de regulação na implementação do novo modelo de atendimento. Laboreal, 14(2), 62-78. https://doi.org/10.4000/laboreal.650

Pizo, C., \& Menegon, N. (2010). Análise ergonômica do trabalho e o reconhecimento científico do conhecimento gerado. Revista Produção, 20(4), 657-668.

Primo, R. (2020). Heróis invisíveis, os eletricistas de linha viva e seus artefatos : contribuições da ergonomia e da psicodinâmica do trabalho (Dissertação de Mestrado). Universidade Estadual de Campinas, Faculdade de Ciências Aplicadas, Limeira, Brasil.

Rabelo, L., Castro, M., \& Silva, J. (2016). Dublês do Setor Elétrico : reflexões sobre identidade e trabalho terceirizado. Revista Psicologia : organizações e trabalho. 16(2), 166-175.

Silva, A., Almeida, I., Vilela, R., Mendes, R., \& Hurtado, S. (2018). Acidentes de trabalho e os religadores automáticos no setor elétrico : para além das causas imediatas. Caderno de Saúde Pública, 24(5), 2-13. https://doi.org/10.1590/0102-311x00007517

Silva, N. (2011). Fatores determinantes da carga de trabalho em uma unidade básica de saúde. Ciência \& Saúde Coletiva, 16(8), 3393-3402. https://doi.org/10.1590/

S1413-81232011000900006

SmartLab - Observatório Digital de Saúde e Segurança no Trabalho (MPT-OIT) (2018). Retirado de http://observatoriosst.mpt.mp.br

Souza, S., Carvalho, F., Araújo, T., Koifman, S., \& Porto, L. (2010). Fatores psicossociais do trabalho e transtornos mentais comuns em eletricitários. Revista de Saúde Pública, 44(4), 710-717. https:// doi.org/10.1590/S0034-89102010000400015

Souza, S., Carvalho, F., Araújo, T., Koifman, S., \& Porto, L. (2012). Depressão em trabalhadores de linhas elétricas de alta tensão. Revista Brasileira de Epidemiologia, 15, 235-245. https://doi.org/ 10.1590/S1415-790X2012000200001

Vasconcelos, V., Zanette, E., Filho, J., \& Merino, E. (2011, 13 de agosto). Diagnóstico de sintomas musculoesqueléticos em eletricistas de uma concessionária de distribuição de energia elétrica. Comunicação apresentada no VII Congresso nacional de excelência em gestão. Rio de Janeiro, Brasil.

Wisner, A. (1987). Por dentro do trabalho : ergonomia, método e técnica. São Paulo : FTD/Oboré.

\section{NOTAS}

1. [1] Em 2014, a FUNCOGE privatizou seus dados, por essa razão, somente estão disponíveis os dados de até 2013. 
2. O Passo Operacional Padrão (POP) é um documento organizacional que traduz o planejamento do trabalho a ser executado. É uma descrição detalhada de todas as medidas necessárias para a realização de uma tarefa.

3. Direito de recusa é previsto na NR 9 e diz respeito ao direito que o trabalhador tem de se recusar a realizar um trabalho em condições de risco iminente: NR 9 - 9.6.3 O empregador deverá garantir que, na ocorrência de riscos ambientais nos locais de trabalho que coloquem em situação de grave e iminente risco um ou mais trabalhadores, os mesmos possam interromper de imediato as suas atividades, comunicando o fato ao superior hierárquico direto para as devidas providências.

\section{RESUMOS}

Este artigo tem como objetivo analisar as problemáticas enfrentadas por eletricistas de linha viva (ELV) de redes de distribuição de energia elétrica no que diz respeito aos aspectos relacionados ao trabalho na tarefa de poda de vegetação.

Para isso realizou-se a aplicação da Análise Ergonômica do Trabalho (AET) de forma adaptada. Posteriormente foram realizadas entrevistas semiestruturadas com a equipe de LV, sendo que as falas foram tratadas conforme a Análise de Conteúdo e discutidas na perspectiva da Ergonomia da Atividade e da Psicodinâmica do trabalho. As dificuldades enfrentadas pelos ELV não dizem respeito somente aos aspectos fisiológicos decorrentes dos esforços empreendidos frente a alta demanda, mas sobretudo referentes aos dispositivos técnicos e organizacionais do trabalho. No entanto, foi possível identificar aspectos ligados à dimensão do prazer associados às questões de ofício, do trabalho bem-feito e aparentemente invisível para a sociedade.

Este artículo tiene como objetivo analizar los problemas a los que se enfrentan los electricistas de línea viva (ELV) de las redes de distribución de energía eléctrica en cuanto a los aspectos relacionados con el trabajo en la tarea de poda de vegetación. Para ello, se aplicó el Análisis Ergonómico del Trabajo (AET) de forma adaptada. Posteriormente, se realizaron entrevistas semiestructuradas con el equipo de ELV y las respuestas fueron tratadas según el Análisis de Contenido y discutidas desde la perspectiva de la Ergonomía de la Actividad y de la Psicodinámica del Trabajo. Las dificultades a las que se enfrenta el equipo de ELV no sólo están relacionadas con los aspectos fisiológicos derivados de los esfuerzos realizados frente a la alta demanda, sino principalmente con los dispositivos técnicos y organizativos del trabajo. Sin embargo, fue posible identificar aspectos vinculados a la dimensión del placer asociados a las cuestiones del oficio, del trabajo bien hecho y aparentemente invisible para la sociedad.

Cet article a pour but d'analyser les problèmes rencontrés par les électriciens, œuvrant sous tension (ELV) dans des réseaux de distribution d'énergie électrique, concernant la tâche d'élagage de la végétation. L'analyse ergonomique du travail (AET) a été appliquée sous une forme adaptée. Ensuite, des entretiens semi-structurés ont été menés avec l'équipe de ELV, et leur contenu a été soumis à une analyse de contenu et discutés dans la perspective de l'ergonomie de l'activité et de la psychodynamique du travail. Les difficultés rencontrées par les ELV ne sont pas seulement liées aux aspects physiologiques découlant des efforts fournis face à une forte demande, mais surtout aux dispositifs techniques et organisationnels du travail 
Cependant, il a été possible d'identifier des aspects liés à la dimension du plaisir associé à des questions du métier, du travail bien fait et apparemment peu visible pour la société.

This article aims to analyze the problems faced by live-line electricians (ELV) of electrical power distribution networks with regard to aspects related to work in the task of pruning vegetation. To this end, an adapted version of the Ergonomic Analysis of Work (EAW) was applied. Subsequently, semi-structured interviews were conducted with the ELV team, and the speeches were treated according to content analysis and discussed from the perspective of Activity Ergonomics and Psychodynamics of Work. The difficulties faced by the ELV team are not only related to the physiological aspects resulting from the efforts made in the face of high demand but are also mainly related to the technical and organizational devices of the work. However, it was possible to identify aspects linked to the dimension of pleasure associated with issues of craft, of work well done and apparently invisible to society.

\section{ÍNDICE}

Keywords: ergonomic analysis of work, linemen, electrical sector, psychodynamics of work Palabras claves: análisis ergonómico del trabajo, psicodinámica del trabajo, electricista de línea viva, sector eléctrico

Palavras-chave: análise ergonômica do trabalho, psicodinâmica do trabalho, eletricista de linha viva, setor elétrico

Mots-clés: analyse ergonomique du travail, psychodynamique du travail, électricien de ligne sous tension, secteur électrique

\section{AUTORES}

\section{MARCELLA SILVA RIBEIRO GONÇALVES}

Faculdade de Ciências Aplicadas, Universidade Estadual de Campinas - Unicamp, Rua Pedro Zaccaria, 1300, Jd. Sta Luzia, CEP 13484-350 - Limeira, SP - Brasil

mrcllribeiro@hotmail.com

\section{SANDRA FRANCISCA BEZERRA GEMMA}

Faculdade de Ciências Aplicadas, Universidade Estadual de Campinas - Unicamp, Rua Pedro Zaccaria, 1300, Jd. Sta Luzia, CEP 13484-350 - Limeira, SP - Brasil gemma@unicamp.br

\section{FLAVIA TRALDI DE LIMA}

Faculdade de Educação, Universidade Estadual de Campinas - Unicamp, Cidade Universitária Zeferino Vaz - Barão Geraldo, Campinas, SP, 13083-970 flaviatraldi@hotmail.com

\section{RENAN PRIMO}

Faculdade de Ciências Aplicadas, Universidade Estadual de Campinas - Unicamp, Rua Pedro Zaccaria, 1300, Jd. Sta Luzia, CEP 13484-350 - Limeira, SP - Brasil renan.unicamp@gmail.com

\section{MILTON SHOITI MISUTA}

Faculdade de Ciências Aplicadas, Universidade Estadual de Campinas - Unicamp, Rua Pedro Zaccaria, 1300, Jd. Sta Luzia, CEP 13484-350 - Limeira, SP - Brasil milton.misuta@fca.unicamp.br 


\section{JOSÉ LUIZ PEREIRA BRITTES}

Faculdade de Ciências Aplicadas, Universidade Estadual de Campinas - Unicamp, Rua Pedro Zaccaria, 1300, Jd. Sta Luzia, CEP 13484-350 - Limeira, SP - Brasil jose.brittes@fca.unicamp.br

\section{AMANDA LOPES FERNANDES}

Companhia Paulista de Força e Luz - CPFL, Rod. Eng. Miguel Noel Nascentes Burnier, ํo 1755 Parque São Quirino, Campinas, SP, 13088-900

amandaf@cpfl.com.br

\section{ELIEZER SILVA FRANCO}

Companhia Paulista de Força e Luz - CPFL, Rod. Eng. Miguel Noel Nascentes Burnier, nํ 1755 Parque São Quirino, Campinas, SP, 13088-900

esilvafranco@cpfl.com.br 